\title{
Serious Games Conferences and Events
}

\author{
C. Vaz de Carvalho
}

GILT-ISEP, Rua Dr. António Bernardino de Almeida, 431, P-4200-072 Porto, Portugal

\section{Abstract}

Serious Games is an evolving subject for researchers and practitioners. More and more events take place with the focus or at least with some side attention given to this subject. We present some of these events as a support tool for potential authors in the selection of the best places to publish their work.

Keywords: Serious Games conferences, Serious Games events.

Received on 01 May 2014, published on 22 May 2014

Copyright (c) 2014 C. Vaz de Carvalho licensed to ICST. This is an open access article distributed under the terms of the Creative Commons Attribution licence (http://creativecommons.org/licenses/by/3.0/), which permits unlimited use, distribution and reproduction in any medium so long as the original work is properly cited.

doi: 10.4108/sg.1.2.e2

iGBL 2014: $4^{\text {th }}$ Irish Symposium on Game-BasedLearning and SEGAN conference ( $6^{\text {th }}$ June, Cork, Ireland)

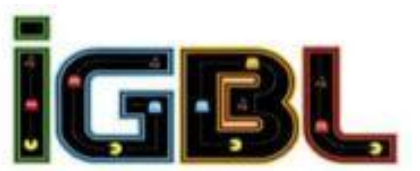

The Cork Institute of Technology, in partnership with the SEGAN network, will host the 4th Irish Symposium on Game-Based-Learning (iGBL) as a oneday event in the Cork Institute of Technology on Friday 6th June 2014.

The iGBL conference is an international conference designed to share insight and experience with regard to the educational potential of games. The conference has always aimed to be as inclusive as possible, bringing together teachers, students, researchers and industry representatives who share a common interest in using games for learning. The conference offers opportunities to present, discuss and network with other like-minded practitioners, as well as providing a great opportunity for those new to the area to learn more about the different development approaches and educational applications of games.

The iGBL2014 conference will present an energetic and compelling programme with a focus on new developments in games and game-based learning, emerging approaches to game-based learning and how these can be implemented in formal education. The theme for iGBL2014 maintains the strands of interest that were established in previous conferences while focusing on the core theme of "The growth of GBL"

Holding fast to iGBL's history of inclusiveness, contributions are welcome within a wide range of topics and areas, from representatives from both industry and academia. Completed research projects, such as action research, case studies and work-in-progress/posters are also welcome. Research-based submissions may include theoretical and/or empirical studies employing qualitative or quantitative methods. Proposals for workshops and interactive posters are also invited.

As part of the programme, CIT's department of Media Communications and Department of Online Delivery, in association with the SEGAN (Serious Games Network) EU-funded project (http://seriousgamesnet.eu) will also be hosting a summer school during the four days leading up to the conference (i.e., 2nd - 5th June 2014 inclusive). This summer school will be focused on teaching second level students how to design and develop educational games. The students will present their ideas during a poster session at the conference.

Site: http://igblconference.wordpress.com/

British HCl Conference 2014 (9-12 September, Southport, UK)

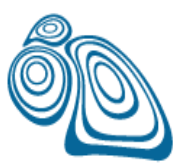

hci 2014 Sand, Sea and Sky Holiday $\mathrm{HCl}$
The HCI 2014 'Hands-on' Showcase gives opportunities for 
researchers, practitioners, designers, artists and industry professionals to demonstrate innovative interaction and interface technologies. This venue will allow conference attendees to experience new developments in HCI research and exhibitors to engage with attendees through the actual use of their systems and discuss their work with their peers.

The special SEGAN Symposium event, "SEGAN HCI in Serious Games" will take place on Wednesday, 10th September 2014. The one hour and half session will be one of the main BHCI parallel sessions in the afternoon, and will be open to all conference attendees.

Site: http://hci2014.bcs.org/

INTERACCION 2014: XV International Conference on Human Computer Interaction (1012 September, Tenerife, Spain)

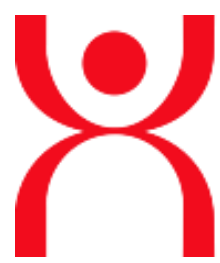

Interacción 2014 is the 15 th edition of the International Conference promoted by the Spanish Asociación para la Interacción Persona-Ordenador (AIPO), whose main objective is to promote and disseminate the recent advances in the field of HumanComputer Interaction. This conference will provide a forum for discussion and exchange of ideas on design and application of techniques and methodologies with a multidisciplinary approach.

The 15th International Conference Interacción 2014 will be organized by the Department of Engineering on Systems and Automatic of University of La Laguna, and will have the support of the Depatment of Systems of the University of Cauca and the Faculty of Computing and Information Technology at the King Abdulaziz University.

The Special Track on Serious Games is a multidisciplinary approach to the presentation of research, theory, application, practice and validation in the field of Serious Games for any level and any area. As such it will cover areas like cognition, psychology, technologyenhanced education, evaluation and assessment, multimedia and information technology.

Site: http://interaccion2014.ull.es/

ELEOT - 1st International Conference on eLearning, e-Education and Online Training (18-20 September, Bethesda, USA)

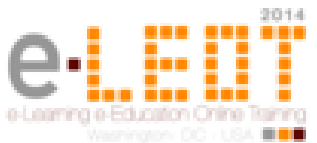

E-Learning has been adopted and endorsed by some of the most prestigious universities. Stanford, Harvard and MIT are leading the way with highly successful online course programs, congruent with a prominent movement towards universal access to quality information and education. This movement has also disrupted the publishing industry, allowing many students to access valuable research through a myriad of open access journals.

This conference will assess the most progressive and exciting ideas for the future of e-Learning. This is truly an incredibly valuable movement as we move towards a flatter information structure for anyone who wants to learn. One of the most relevant topics of the conference will be focusing on Serious Games.

Site: http://eleot.org/2014/show/home

\section{ECGBL 2014: $8^{\text {th }}$ European Conference on Games Based Learning (9-10 October, Berlin, Germany)}

Theoretical and practical work in the area of Edutainment, Serious Games \& Play as well as GameBased Learning have advanced the field with both best as well as worst practices. Applied learning theories differ behaviourism and skill \& drill, cognitivism, constructivism, constructionism - all having their merits and pitfalls. New technologies, concepts and usage patterns arise (e.g. cheap motion-tracking, Gamification, mobile gaming) while other hypes subside (see social/Facebook games). All of this and more makes Game-Based Learning such an intriguing field, but also one that needs input from all areas of art, science, business and education/training.

ECGBL 2014, the $8^{\text {th }}$ European Conference on Gamebased Learning is an opportunity for the presentation of research, theory, application, practice and validation in the field. Throughout the years, ECGBL has been addressing this issue by providing a forum to exchange ideas and best practice among researchers and practitioners therefore contributing to a wider adoption of GBL in Europe.

Hosted by Research and Training Center for Culture and Computer Science (FKI) of the University of Applied Sciences HTW Berlin, ECGBL 2014 will take place in Berlin, Germany, on 9-10 October 2014.

Site: http://academicconferences.org/ecgbl/ecgbl2014/ecgbl14-home.htm 